\title{
Mindfulness Is Linked with Affectivity in Daily Life: An Experience-Sampling Study with Meditators
}

\author{
Wolfgang Tschacher $^{1}$ (D) Noëmi Lienhard ${ }^{2}$
}

Accepted: 28 February 2021 / Published online: 1 April 2021

(C) The Author(s) 2021

\begin{abstract}
Objectives An increasing number of findings indicate associations between mindfulness and affect as well as mindfulness and stress. Most studies have conceptualized and measured these variables on a trait level, often in student samples or clinical contexts.

Methods We adopted an experience-sampling approach to measure mindfulness, affect, and stress repeatedly as states in naturalistic environments. In assessing mindfulness, we factorized items from the trait questionnaire CHIME to conceptualize state mindfulness, finding two mindfulness facets labeled Awareness and Acceptance. Affect was measured using the Positive and Negative Affect Schedule, and perceived stress was rated by a single item. Data was gathered by a smartphone app that prompted participants six times a day for 10 consecutive days. Using hierarchical regression, we examined associations at the same time-point as well as with time lags, in order to also elucidate Granger causal relationships. Fifty-six practicing meditators participated in this study.

Results Concerning the associations of state mindfulness facets with affectivity at the same time, both Awareness and Acceptance were linked with positive affect and negatively with stress. Negative affect was associated negatively with Acceptance. The lagged analyses suggested the Granger causal interpretation that Acceptance reduced negative affect. We also found reversed lagged effects, in that positive affect attenuated subsequent Awareness and negative affect subsequent Acceptance.

Conclusions The bidirectional Granger causal effects between mindfulness and affect challenged a one-sided interpretation of mindfulness-affect associations. One implication for psychotherapy may be to clarify why mindfulness and resilience (i.e., therapists' hardiness with respect to adversity) are properties of efficient therapists.
\end{abstract}

Keywords Affect - Comprehensive Inventory of Mindfulness Experiences (CHIME) - Experience sampling method (ESM) . Meditators $\cdot$ State mindfulness $\cdot$ Stress

Over the past decades, the academic interest in mindfulness has increased steadily throughout psychology and health sciences (Brown et al., 2015b), with the mindfulness concept rooted in the teachings of the historical Buddha (Analayo, 2019; Bodhi, 2011). Both traditionally and in current practice, meditation is seen as the primary means to foster mindfulness (Gethin, 2001; Sedlmeier et al., 2012). The concept of mindfulness has been defined in a variety of different ways

Wolfgang Tschacher

wolfgang.tschacher@upd.unibe.ch

1 Universitätsklinik für Psychiatrie und Psychotherapie, Universität Bern, Bolligenstrasse 111, 3060 Bern, Schweiz

2 Psychiatriezentrum Münsingen, Hunzigenallee 1, 3110 Münsingen, Schweiz
(Grossman, 2008), so that its operationalization varies considerably between authors (Sauer et al., 2013). Constructs range from one-factorial (e.g., Brown \& Ryan, 2003; Chadwick et al., 2008) to multifactorial (e.g. Baer et al., 2006; Cardaciotto et al., 2008). According to Bishop et al. (2004), mindful people regulate attention toward the present moment and are oriented with acceptance, curiosity, and openness toward their own immediate experiences. Mindfulness is also characterized by adopting a decentered perspective on own experiences, by understanding the subjective and transient character of experience, and by the ensuing meta-cognitive insights into mental processes. This multifactorial or multivalent (Analayo, 2019; Baer, 2019) definition is grounded in the historical traditions of mindfulness and consistent with the comprehensive approach of Bergomi et al. (2014), which acknowledges several facets of the mindfulness concept. 
The scientific psychological literature has focused predominantly on investigating mindfulness as a trait, and most instruments are constructed as trait questionnaires (e.g., Baer et al., 2008; Brown et al., 2015b; Sauer et al., 2013). Only recently, researchers have started to complement this dominance of the trait approach with longitudinal studies in daily life, often with a focus on mindfulness as a means of emotion regulation (Blanke et al., 2018; Brockman et al., 2017; Wenzel et al., 2020). In line with this trend, we believe that shifting the focus on investigating mindfulness as a state has advantages. First, all mindfulness definitions emphasize that mindfulness arises as a moment-to-moment process of directing attention toward the immediate experience now (Bishop et al., 2004). The assessment of general levels of mindfulness across individuals rather neglects this momentcentered quality. Second, the within-person variation of mindfulness and its relation to the within-person variation of other variables cannot be assessed when mindfulness is only measured as a trait. Third, measurement of trait mindfulness is susceptible to retrospective bias because mindfulness is not captured as it occurs but rated after the fact (Shiffman et al., 2008). Fourth, an exclusive focus on between-person comparisons aggravates the problem of self-assessment of mindfulness, as more mindful people are also more likely to notice periods of distraction (Grossman, 2008) and the wording of mindfulness items is interpreted differently by people with and without meditation practice (Belzer et al., 2013). All these tendencies can lead to distorted findings on the association between mindfulness and other variables. Most of these problems, in our opinion, can be avoided by investigating mindfulness in the present moment, as a state, and by addressing meditators who have a solid understanding of the concept.

Until recently, the effects of state mindfulness on other variables were mainly examined by means of experimental laboratory studies, where mindfulness was induced by short interventions (e.g., Broderick, 2005; Ditto et al., 2006). Such studies, however, have attenuated external validity. A preferable option for the investigation of state variables is the experience sampling method (ESM), a type of ambulatory assessment (Trull \& Ebner-Priemer, 2014). ESM is the repeated monitoring of momentary experience and/or behavior in a participant's normal environment, which allows capturing state variables outside the lab. Using this method, momentto-moment experiences can be measured repeatedly, and within-person associations can be assessed. ESM improves ecological validity, provides data on the temporal dynamics of behavior and experience, and is less susceptible to retrospective bias than standard questionnaire methods (Delespaul, 1995; Shiffman et al., 2008). There is a large literature on the assessment of momentary emotional and affective variables (e.g., Kockler et al., 2017), and the technological and computational devices for ambulatory assessment have developed rapidly (Tröndle et al., 2014; Walsh et al., 2019).
Mindfulness has been investigated in relation to many different constructs. Numerous studies have reported associations with various positive psychological variables, such as lower stress (e.g., Weinstein et al., 2009), favorable personality characteristics (e.g., Giluk, 2009), resilient regulation in response to pain (e.g., Wright \& Schutte, 2014), and more positive and less negative affect (e.g., Brown \& Ryan, 2003; Giluk, 2009). In the present study, we focused on the association between mindfulness and affect as well as stress. These associations have been investigated in several studies assessing mindfulness on a trait level, as well as in studies using mindfulness-based intervention designs. In a metaanalysis of data primarily from trait questionnaires, Giluk (2009) showed that mindfulness had a moderate positive association with positive affect and a moderate negative association with negative affect. These results have been confirmed in numerous studies (e.g., Anderson et al., 2007; Bergomi et al., 2013; Geschwind et al., 2011; Nyklícek \& Kuijpers, 2008; Shapiro et al., 2007). Additional support for the associations with affect came from studies that experimentally induced mindfulness (e.g., Arch \& Craske, 2006; Broderick, 2005; Erisman \& Roemer, 2010). These experimental studies have provided a causal interpretation of an association from mindfulness toward affect.

The early ESM study of Brown and Ryan (2003) has focused on the association of mindfulness and affect during everyday activity. The authors found that affect was predicted more strongly by state mindfulness than by trait mindfulness. They investigated associations at the same point in time and did not model time-lagged effects. State mindfulness was assessed with a short form of the one-factorial Mindful Attention Awareness Scale (MAAS), which measures mindfulness as attention regulation toward the present moment. The sample was from the general population and consisted of non-meditators. Three more recent studies were based on student samples. A study with assessments using daily diaries reported reciprocal relationships between mindfulness and negative affect, with mindfulness predicting reduced negative affect the next day and vice versa (Brockman et al., 2017). In their ESM study with multiple monitorings in daily life, Blanke et al. (2018) found that the facets "present-moment attention" and "nonjudgmental acceptance" independently increased positive affect, whereas acceptance in interaction with attention played a pivotal role for decreasing negative affect. Wenzel et al. (2020) conducted two ESM studies showing that mindfulness, especially its acceptance facet, reduced negative affect and the need for emotion regulation. Thus, there is increasing support of a link between mindfulness and affectivity in daily life.

Some further ESM studies have been conducted in the context of mindfulness-based interventions (Shoham et al., 2017; Snippe et al., 2017; Walsh et al., 2019). ESM data have pointed to "upward spirals" between affect and 
cognition (Garland et al., 2015) and between mood and mindfulness (Gotink et al., 2016) due to mindfulness trainings. The ability to differentiate positive and negative emotions was found mediated by levels of mindfulness but depended on the emotion levels in a clinical sample (van der Gucht et al., 2019). Snippe et al. (2017) reported, based on daily self-assessments, that negative affect and perceived stress were reduced when participants were involved in a mindfulness-based stress reduction program, but the link between affect and stress remained constant. With respect to the relationship between mindfulness and emotional experience, Shoham et al. (2017) found associations between mindfulness and positive emotional valence in daily living as well as in meditation contexts.

Conducting a study in daily living contexts without interventions, yet involving people who already have meditation experience, may shed new light on the relationship between state mindfulness and affect. Meditators show generally higher levels of mindfulness, especially in the mindfulness facet of acceptance, and moderately higher levels in the facet of awareness (Bergomi et al., 2015). Meditation practice was often found to improve the validity of mindfulness self-assessments, whereas naive participants without meditation experience tended to misinterpret self-report items, such as the word "experience" (Bergomi et al., 2013). Belzer et al. (2013) even reported non-meditators having severe comprehension problems in a majority of the items of a standard mindfulness questionnaire. Such validity concerns may thus be avoided by recruiting experienced meditators in a study.

In the present study, we investigated the associations of mindfulness with affect and stress on a state level with an ESM approach involving meditators only. Using hierarchical regression, we modeled these associations at the same point in time as well as time-shifted associations, in order to uncover the direction of the effects. Based on the previous research and depending on the facets derived from the ESM scale, we hypothesized that the facets of state mindfulness were associated with positive affect and (negatively) with negative affect (H1a, H1b). Hypothesis $\mathrm{H} 2$ concerned stress, assuming that facets of mindfulness were negatively linked to perceived stress. $\mathrm{H} 1$ and $\mathrm{H} 2$ referred to variables measured at the same point in time $t$. Further hypotheses stated that time-lagged mindfulness facets (previous state mindfulness at $t-1$ ) predicted affect monitored at time $t$ (H3a for positive affect, $\mathrm{H} 3 \mathrm{~b}$ for negative affect) and stress monitored at time $t(\mathrm{H} 4)$. To control for the direction of time-lagged associations, we repeated the modeling with inverted direction of effects thus testing $\mathrm{H} 3 \mathrm{a}, \mathrm{H} 3 \mathrm{~b}$, and $\mathrm{H} 4$ in reversed sequence. In addition, we conducted exploratory analyses on the relationship of state mindfulness with trait measures of personality, emotional competence, and psychopathological distress.

\section{Method}

\section{Participants}

Several Buddhist meditation groups in Switzerland were approached personally by one of the authors to invite individuals to this study. The inclusion criteria were meditation experience in one of the Buddhist traditions and fluency in the German language. Participation in the study was fully voluntary; no gratification was offered except for general feedback on findings after completion (after which mail addresses were to be destroyed). Thus, after the study period, the dataset was anonymized, as no names, dates of birth, or addresses were recorded. The presentation to the groups informed that the study was on mindfulness and consisted of two parts, a questionnaire part and a part to be completed in everyday life, which would depend on the availability of participants' smartphones. Of 67 individuals responding, eleven were excluded who did not initiate the study owing to technical issues. The remaining sample consisted of 56 participants, of whom $59 \%$ were female. The 11 individuals who did not enter the second part of the study were not significantly different from completers with respect to age, sex, meditation experience, or education level. All participants were of Caucasian ethnicity. Their mean age was 42.4 years ( $\mathrm{SD}=12.8$, range $20-68$ ). The level of education reported by participants was high: $35.7 \%$ of the participants reported having a master's degree, $25 \%$ a bachelor's degree, $23.2 \%$ secondary education, and $16.1 \%$ an apprenticeship diploma. All participants declared both having meditation experience and practicing currently. Experience in meditation ranged from 6 months to 35 years with a mean of 10.3 years $(\mathrm{SD}=9.0)$. Current meditation time per week ranged from 0.25 to $15 \mathrm{~h}$ with a mean of 3.3 $(\mathrm{SD}=3.0)$. Based on participants' statements, it was possible to categorize the type of meditation (except for $7.2 \%$ of participants) into the following three groups of Buddhist meditation practice: Theravada-Vipassana (50\%), Vajrayana-Tibetan (23.2 \%), and Mahayana-Zen (19.6\%). These three categories corresponded roughly to the three main branches of Buddhism (Harvey, 2013).

\section{Procedures}

The study consisted of a trait part with one-time online questionnaires and a state part implementing the experience sampling method (ESM). The study language was German. For ESM, the app MetricWire (http://metricwire.com) was used, which runs on different smartphone operating systems. The advantages of using smartphones for ESM are their high distribution as well as low invasiveness compared to other forms of ESM data collection. Other than by means of smartphones, previous ESM data collection required either additional electronic devices or reminder devices combined 
with separate questionnaires that participants carry with them (e.g., Geschwind et al., 2011; Hill \& Updegraff, 2011).

After participants' consent, e-mails provided them online access to the trait questionnaires. After completion of the questionnaires, participants installed MetricWire on their smartphones to enter the ESM part of the study. Participants were free to initiate the ESM part within an interval of 3 months, and the study then continued for 10 consecutive days. Participants were prompted to complete the survey six times each day between 9:30 am and $10 \mathrm{pm}$. The prompts were timed randomly with a minimum interval of $90 \mathrm{~min}$ in between (Fig. 1). If participants did not respond $15 \mathrm{~min}$ after the prompt, they received a reminder, and after $60 \mathrm{~min}$ of no response, the survey disappeared from the device. Each prompted survey contained in fixed order a block of questions related to mindfulness, then a block related to affect, and finally the stress item. Questions within blocks were presented in random sequence. Each individual survey took roughly 2 min to complete. When participants failed to respond to the prompts for a prolonged period of time, they were contacted by e-mail to rule out possible technical problems.

\section{Measures}

\section{Demographic Characteristics and Meditation Experience}

Participants were asked to report their age, sex, and their highest educational attainment. Since experience in meditation was a prerequisite for this study, the first question about meditation in the trait questionnaire screened participants to ensure that only those with meditation experience were included. Participants were asked the tradition they felt most affiliated with, the meditation techniques they used, years of experience, as well as the duration and frequency of their current meditation practice.

\section{Personality Traits}

The BFI-K is the 21-item short form of the Big Five Inventory (German version NEO-FFI: Borkenau \& Ostendorf, 1993), offering an economic description of personality by five factors Extraversion, Agreeableness, Conscientiousness, Neuroticism, and Openness for new experiences. In the literature, the psychometric properties of the BFI-K were found satisfactory (Rammstedt \& John, 2005), with acceptable reliability of $r=.76$, factorial validity, and good convergence of self-reports with partner ratings and other personality questionnaires.

\section{Emotion Regulation Skills}

The SEK-27 is a self-report instrument for the assessment of emotion regulation skills (Selbsteinschätzung emotionaler Kompetenzen [SEK]: Berking \& Znoj, 2008). On 27 items, competences for adaptive emotion regulation are rated. According to these authors, the SEK-27 showed Cronbach's $\alpha$ of 0.90 for the global score, and its retest reliabilities after 2 weeks were $r=.75$. Here we used the global score of the SEK27 exclusively.

\section{Psychological Distress}

The Symptom Checklist-90 (SCL-90) (Derogatis, 1977) is a standard questionnaire used to assess psychological distress and symptom load. The global severity index (GSI) of the short form SCL-K-9 shows high reliability, with a correlation between the GSI-9 and the full GSI-90 of $r=.93$ (Petrowski et al., 2019). They reported acceptable to good Cronbach's $\alpha$ of items supporting a unidimensional interpretation of the SCL-90. In this study, we used the GSI of the SCL-K-9.

\section{Trait Mindfulness}

Trait mindfulness was assessed with the Comprehensive Inventory of Mindfulness Experiences (CHIME: Bergomi et al., 2014), which measures mindfulness on eight scales: (1) attending to inner experiences (Inner awareness), (2) attending to external experiences (Outer awareness), (3) acting with awareness (Acting with awareness), (4) nonjudgmental and accepting attitude (Acceptance), (5) non-reactivity to experience/decentered attitude (Decentering), (6) willingness and readiness to expose oneself to experiences/non-avoidance (Openness), (7) understanding of the relativity of thoughts and emotions (Relativity), and (8) insightful understanding into the working of the mind (Insight). The CHIME was constructed based on theoretical considerations, on operationalizations by
Fig. 1 Schema of the experience sampling procedure

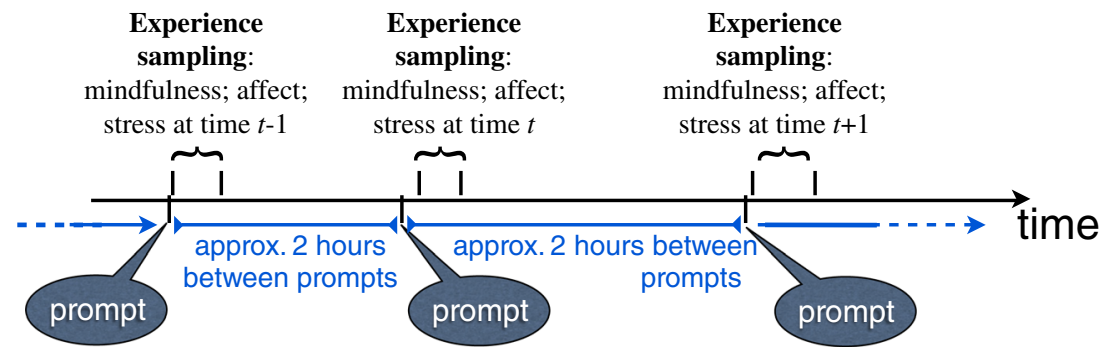


previous questionnaires and empirical evidence. The 37 items in the CHIME are rated on 6-point Likert scales (1. almost never, to 6, almost always) with respect to the last 2 weeks. Higher scores indicate higher levels of mindfulness. Testretest reliabilities of all subscales in the study by Bergomi et al. (2014) were acceptable with values $\geq 0.70$, and single scales as well as total scores exhibited good validity.

\section{State Mindfulness}

State mindfulness was measured with the Comprehensive Inventory of Mindfulness Experiences for ESM (CHIMEESM), a short questionnaire consisting of six items based on the CHIME. We developed the CHIME-ESM specifically for this study. One item of each original CHIME scale was chosen according to the following criteria: (1) high factor loading, (2) applicability to a broad variety of situations, and (3) meeting the requirements of a state item. Items from the scale Relativity were deemed unsuitable because of insufficient applicability to different situations. Items from the scale Insight were also deemed unsuitable because of the strong trait character of this scale. Thus, these scales were not considered. Furthermore, the rating scale was changed from a frequency to an intensity scale to support state assessments. CHIME-ESM items were rated on 6-point Likert scales (1, not at all, to 6, very strongly), and participants were asked to consider the 10-min interval prior to the prompt for their self-assessments. We avoided referring to the present moment, as mindfulness is changed as soon as inquired upon: Awareness of the present moment, for example, is necessarily given when this awareness is questioned by an item. Table 1 lists the CHIME-ESM items together with the corresponding CHIME scales.

\section{Affect}

State values of Positive affect (PA) and Negative affect (NA) were assessed using the International Positive and Negative Affect Schedule Short Form (I-PANAS-SF: Thompson, 2007) translated following the German translation of the
Positive and Negative Affect Schedule (PANAS) by Krohne et al. (1996). PA and NA are frequently used in research on emotion regulation, resilience (i.e., hardiness in the face of adversity; Kuranova et al., 2020), and throughout mindfulness studies. In the I-PANAS-SF, five items for both PA and NA are rated on a 5-point Likert scale (1, never, to 5, always) in regard to the $10 \mathrm{~min}$ prior to the prompt. PA comprises the items alert, inspired, determined, attentive, and active, and NA the items upset, hostile, ashamed, nervous, and afraid. Higher scores in both cases indicate higher levels of PA and NA. Cronbach's $\alpha$ of both scales is acceptable in Thompson's original study with 0.76 for NA and 0.75 for PA. Cronbach's $\alpha$ was good in the present study with 0.86 for NA and 0.85 for PA.

\section{Perceived Stress}

Stress was assessed using a single item "In the past $10 \mathrm{mi}$ nutes, I was stressed out" on a 5-point Likert scale (1, not at all, to 5 , extremely).

\section{Data Analyses}

The first step of data analysis was inspecting the intercorrelations of the six CHIME-ESM items. The item scores were averaged for each participant across the 56 participants, and we conducted maximum likelihood factor analysis with varimax rotation to possibly reduce the six items to orthogonal factors for parsimonious statistical modeling. The number of factors was determined by chi-square tests. This and further statistical analyses were performed using JMP Pro 15.1 (SAS Institute Inc., Cary NC).

Second, the scales of the state CHIME-ESM were described by the validated trait CHIME and the other trait questionnaires BFI-K (personality), SEK-27 (emotion regulation skills), and SCL-K-9 (psychological distress). To do this, participants' mean CHIME-ESM factors were correlated pairwise with the CHIME scales, the Big Five factors of the

Table 1 Items of the CHIME-ESM with corresponding trait-CHIME scale

not at all / minimally / a little / clearly / strongly / very strongly

(1) I clearly noticed changes in my body, such as quicker or slower breathing. [M=3.22, $\mathrm{SD}=0.82]$

Inner awareness

(2) I noticed sounds in my environment, such as birds chirping or cars passing. [M=3.01, SD=0.77]

(3) I was able to observe my thoughts and feelings without getting tangled up in them. $[\mathrm{M}=3.53, \mathrm{SD}=0.86]$

(4) I tried to avoid unpleasant emotions and thoughts. [M=5.15, $\mathrm{SD}=0.49]$

(5) I judged myself as good or bad. [M=4.95, $\mathrm{SD}=0.62]$

(6) I got distracted by memories, images, or reverie. $[\mathrm{M}=4.86, \mathrm{SD}=0.63]$
Outer awareness

Decentering

Openness

Acceptance

Acting with awareness

Note: Original German items translated into English following Johnson et al. (2017). Items (4) to (6) have reversed scoring. M, aggregated individual mean; SD, standard deviation 
BFI-K, the global SEK-27 score, and the GSI of the SCL-K-9, in order to explore the validity of the CHIME-ESM.

After these two preparatory steps, the main analyses applied hierarchical linear modeling to assess hypotheses H1 and $\mathrm{H} 2$ on the links between mindfulness (predictor) and positive affect (H1a) and negative affect (H1b). Positive and negative affect and stress were the dependent variables in these models, respectively. As the variable "perceived stress" (H2) was not distributed normally, we applied hierarchical logistic regression modeling using the glmer function in the lme 4 package for R (Bates et al., 2015). When stress was the dependent variable, we dichotomized this variable ( 0 , no stress; 1 , stress) to enable hierarchical models. This split at the median $=1$ of the stress data was also suggested by the generally low stress levels reported, with $54 \%$ of responses reporting no stress. Using Akaike's information criterion (AIC) as a measure of model fit, we increased model complexity stepwise by successively adding fixed effects and random effects (random intercepts and random slopes) to detect the minimum AIC. Interaction effects were not considered owing to the orthogonality of the two mindfulness factors. All predictor variables, with the exception of the ordinal stress predictor, were centered in the participants' mean values.

This procedure was repeated by inserting lagged predictors $(t-1)$, thus testing hypotheses $\mathrm{H} 3 \mathrm{a}, \mathrm{H} 3 \mathrm{~b}$, and $\mathrm{H} 4$. The analyses with lagged predictors were intended to assess Granger causal relationships, since significant time-lagged predictions can be useful surrogates of causal predictions. To assess $\mathrm{H} 3 \mathrm{a}$ and $\mathrm{H} 3 \mathrm{~b}$, we first modeled the impacts of previous mindfulness facets (lagged predictors) on positive affect, negative affect, and stress (dependent variables). Then we examined Granger causality by mindfulness facets as dependent variables and lagged affect and stress as predictors. To assess H4, perceived stress was used as an ordinal variable when in the role of fixed effect and dichotomized in the role of dependent variable in multilevel modeling using $\mathrm{R}$. In each model concerning $\mathrm{H} 3 \mathrm{a}$, $\mathrm{H} 3 \mathrm{~b}$, and $\mathrm{H} 4$, the respective lagged dependent variable was added to the predictors to account for the autocorrelation of the dependent variable.

\section{Results}

\section{Descriptive Findings of the ESM Part of the Study}

Overall, $n=56$ participants completed 2,033 out of 3,360 surveys; thus a participant's mean number of completed surveys was 36.5 ( $\mathrm{SD}=16.3)$. On average, $16.3 \mathrm{~min}$ elapsed between survey prompt and completion $(\mathrm{SD}=16.2)$. Mean positive affect across all surveys was $3.30(\mathrm{SD}=0.71)$, mean negative affect 1.35 ( $\mathrm{SD}=0.48)$, and mean stress 1.75 ( $\mathrm{SD}=0.98)$. Pearson's correlations of participants' positive and negative affect, computed on the participant-centered variables, were independent in this sample, $r(2022)=-.01(p=.67)$. Stress and affect were positively correlated at the within-participant level: Spearman's correlation of stress with positive affect was $r(2022)=.31(p<.0001)$ and with negative affect $r(2022)=.36$ $(p<.0001)$. The between-participant means of positive affect was $3.28(\mathrm{SD}=0.39)$, of negative affect $1.36(\mathrm{SD}=0.23)$, and of stress $1.73(\mathrm{SD}=0.39)$. The between-participant correlation of mean values of positive and negative affect was $r(52)=.02$ $(p=.89)$; Spearman's correlation of stress with positive affect was $r(52)=.35(p<.01)$ and with negative affect $r(52)=.34$ $(p<.05)$. The within-person reliabilities of affect (Bonito et al., 2012) were derived from the respective unconditional hierarchical models of positive and negative affect, providing reliabilities of 0.83 for positive affect and 0.52 for negative affect.

\section{Factor Analysis of State Mindfulness}

The six CHIME-ESM items were correlated ranging from $r=.01$ to .68 . Maximum likelihood factor analysis on the participants' mean item values using varimax rotation suggested two factors. The communalities ranged between 0.43 and 0.93 . The chi-square test that two factors are sufficient was not rejected, $\operatorname{chi}^{2}{ }_{3 \text { factors }}(4)=1.39, p=.85$. A two-factor solution was also suggested by the scree plot and the eigenvalue $>1$ criterion. We labeled the factors F1-Awareness and F2-Acceptance. The two rotated factors accounted for $61.3 \%$ of the total variance, and the within-person reliabilities (Bonito et al., 2012) were 0.80 (F1-Awareness) and 0.64 (F2-Acceptance). The items representing Inner awareness, Outer awareness and Decentering loaded together on F1-Awareness. F1Awareness indicates states of awareness of current environmental stimuli and perception of momentary bodily and mental processes. The items for Openness, Acceptance, and Acting with awareness, after reversal of the scales, comprised the factor F2-Acceptance. Thus F2-Acceptance represents nonjudgmental states, when the individual also remained open in the face of intruding thoughts, reverie, or memories and was not distracted by mind-wandering or "autopilot." All subsequent analyses were conducted based on these two factors that were regarded as facets of state mindfulness. For information on the rotated factor loadings, see Table 2.

\section{Description and Validation of State Mindfulness}

Pearson's correlations of participants' mean values of the CHIME-ESM with trait questionnaires and demographic variables are given in overview in Table 3 . The state mindfulness factors showed significant correlation coefficients with the corresponding trait mindfulness scales except for the trait Inner awareness, which was linked to both state mindfulness factors. The state factor F1-Awareness was correlated with the "Big Five" personality trait Openness for new experiences, whereas the state factor F2-Acceptance was negatively 
Table 2 Maximum likelihood factor analysis of state mindfulness (CHIME-ESM)

\begin{tabular}{lll}
\hline Items of CHIME-ESM & F1-Awareness & F2-Acceptance \\
\hline (1) Inner awareness & 0.96 & -0.05 \\
(2) Outer awareness & 0.71 & 0.00 \\
(3) Decentering & 0.65 & 0.20 \\
(4) Openness & 0.07 & 0.93 \\
(5) Acceptance & 0.03 & 0.70 \\
(6) Acting with awareness & 0.06 & 0.66 \\
Explained variance: & $30.9 \%$ & $30.4 \%$ \\
\hline
\end{tabular}

Scores of items (4), (5), and (6) were reversed prior to factor analysis. Numbers are factor loadings after varimax rotation

correlated with Neuroticism and Psychological distress. Both state mindfulness factors were correlated with Emotion regulation skills. As for demographic variables, state mindfulness was higher in older participants and not related to participants' sex. F1-Awareness was negatively related to education level, and F2-Acceptance was higher in meditators with more years of practice.

\section{Hierarchical Linear Modeling}

In the hierarchical linear models, the state mindfulness factors F1-Awareness and F2-Acceptance were the fixed effects used to predict the dependent variables Positive affect (H1a), Negative affect (H1b), and Perceived stress (H2). Level 1 was constituted by the single observations of the experience sampling procedure, where participants repeatedly rated their affect, perceived stress, and mindfulness. Level 2 of data concerned the level of the participant, and we computed models assuming random intercepts only, as well as models assuming random intercepts and random slopes. The random effects are described by the variance components, by their standard errors, and by how much of the total variance of a model can be attributed to the respective random effects. In the logistic regressions involving stress, the binomial family of the R package lme 4 was implemented using the logit transformation when testing the probability of stress present (stress=1) or absent (stress $=0$ ). $Z$-tests based on the binomial distribution were used, and thus residuals do not appear in the logistic regression equations and the respective models.

Using the restricted maximum likelihood (REML) method, we tested hypotheses H1a that Positive affect and H1b that Negative affect were associated with state mindfulness facets. The respective best-fitting model (with minimum AIC) for each of the hypotheses is provided in Table 4. Model 1 shows in support of H1a that Positive affect was linked to both F1Awareness and F2-Acceptance in a random intercept and random slope approach. Model 2 shows that F2-Acceptance was negatively associated with Negative affect in a random intercept and random slope model. Higher F2-Acceptance was thus related to less Negative affect consistent with H1b. The best logistic model for the prediction of Perceived stress was Model 3, indicating that stress was negatively linked with both F1-Awareness and F2-Acceptance. Thus both facets were associated with reduced stress. The results of these linear models are listed in Table 4 and summarized in graphical form in Fig. 2.

Tables 5 and 6 give the results of models for the links between facets F1-Awareness and F2-Acceptance and Positive affect, Negative affect, and Perceived stress using time-lagged fixed effects. In all models, the respective lagged version of the dependent variable was included as a fixed effect to control for autocorrelation of the dependent variable. Only the best models according to the AIC criterion are printed in the tables. In all models, the autocorrelation effect was significant. A lag $(t-1)$ indicates that the assessment of the prompt one time step prior to the assessment of the respective dependent variable is used. Table 5 shows how Positive affect, Negative affect, and Perceived stress were predicted by mindfulness facets. Hypothesis H3a that prior mindfulness would predict the increase of Positive affect was not supported. The relationship in Model 5 was significant: Negative affect was predicted negatively by previous F2-Acceptance in concordance with hypothesis H3b. Model 6 concerns the Granger causal link between mindfulness facets and Perceived stress and thus refers to hypothesis 4 . No significant link was found in the logistic hierarchical regressions.

Concerning H3a, Table 6 addresses the modeling of the inverse direction: do affectivity and stress predict subsequent mindfulness facets? Model 7 supported H3a by a negative link between previous Positive affect and F1-Awareness. Concerning H3b in inverse direction, Model 8 was in favor of a negative link between previous Negative affect and subsequent F2-Acceptance. Models 9 and 10 show that previous stress was not Granger causally linked with any of the mindfulness facets, thus not supporting H4. All time-lagged results are shown graphically in Fig. 3. The Granger causal association of Negative affect and F2-Acceptance was found to hold for both temporal directions: F2-Acceptance reduced Negative affect and was itself reduced by Negative affect. Positive affect has an effect only on F1-Awareness, whereas Perceived stress was not significantly involved in Granger causal models.

\section{Discussion}

Our goal was to investigate the associations of mindfulness with affect and stress using an experience sampling method (ESM), which allowed measuring mindfulness with high frequency in a naturalistic, everyday setting. In order to examine these associations, we based our assessment on the multifaceted operationalization of mindfulness derived from the 
Table 3 Correlations of state mindfulness [mean values per participant] with traits and other descriptors

\begin{tabular}{|c|c|c|}
\hline State mindfulness [CHIME-ESM factors] & Trait variables & Correlation \\
\hline F1-Awareness & CHIME-Inner awareness $[\mathrm{M}=4.85, \mathrm{SD}=0.60]$ & $0.49 * * * *$ \\
\hline F2-Acceptance & CHIME-Inner awareness & $0.28^{*}$ \\
\hline F1-Awareness & CHIME-Outer awareness $[\mathrm{M}=4.55, \mathrm{SD}=0.87]$ & $0.40 * *$ \\
\hline F2-Acceptance & CHIME-Outer awareness & 0.12 \\
\hline F1-Awareness & CHIME-Acting with awareness [M=4.21, SD=0.64] & 0.21 \\
\hline F2-Acceptance & CHIME-Acting with awareness & $0.34 *$ \\
\hline F1-Awareness & CHIME-Acceptance $[\mathrm{M}=4.03, \mathrm{SD}=0.82]$ & 0.16 \\
\hline F2-Acceptance & CHIME-Acceptance & $0.35 * *$ \\
\hline F1-Awareness & CHIME-Decentering $[\mathrm{M}=4.19, \mathrm{SD}=0.65]$ & 0.15 \\
\hline F2-Acceptance & CHIME-Decentering & $0.37 * *$ \\
\hline F1-Awareness & CHIME-Openness [M=4.44, SD=0.77] & 0.19 \\
\hline F2-Acceptance & CHIME-Openness & $0.37 * *$ \\
\hline F1-Awareness & "Big Five" Extraversion $[\mathrm{M}=3.67, \mathrm{SD}=0.85]$ & 0.06 \\
\hline F2-Acceptance & "Big Five" Extraversion & -0.18 \\
\hline F1-Awareness & "Big Five" Agreeableness [M=3.50, SD=0.74] & 0.22 \\
\hline F2-Acceptance & "Big Five" Agreeableness & 0.00 \\
\hline F1-Awareness & "Big Five" Conscientiousness $[\mathrm{M}=3.72, \mathrm{SD}=0.82]$ & -0.09 \\
\hline F2-Acceptance & "Big Five" Conscientiousness & 0.14 \\
\hline F1-Awareness & "Big Five" Neuroticism [M=2.75, SD=0.69] & -0.03 \\
\hline F2-Acceptance & "Big Five" Neuroticism & $-0.36^{* *}$ \\
\hline F1-Awareness & "Big Five" Openness for new experiences $[\mathrm{M}=4.28, \mathrm{SD}=0.61]$ & $0.32 *$ \\
\hline F2-Acceptance & "Big Five" Openness for new experiences & -0.21 \\
\hline F1-Awareness & SEK-27 Emotion regulation skills (global score) $[\mathrm{M}=3.93, \mathrm{SD}=0.50]$ & $0.44 * * *$ \\
\hline F2-Acceptance & SEK-27 Emotion regulation skills (global score] & $0.38 * *$ \\
\hline F1-Awareness & SCL-K-9 Psychological distress (GSI) $[\mathrm{M}=0.79, \mathrm{SD}=0.47]$ & 0.14 \\
\hline F2-Acceptance & SCL-K-9 Psychological distress (GSI) & $-0.58 * * * *$ \\
\hline F1-Awareness & Participant's age & $0.31 *$ \\
\hline F2-Acceptance & Participant's age & $0.32 *$ \\
\hline F1-Awareness & Participant's sex ( $0=$ female, $1=$ male $)$ & -0.25 \\
\hline F2-Acceptance & Participant's sex $(0=$ female, $1=$ male $)$ & 0.05 \\
\hline F1-Awareness & Participant's education level & $-0.37 * *$ \\
\hline F2-Acceptance & Participant's education level & 0.09 \\
\hline F1-Awareness & Participant's meditation experience (years) & 0.15 \\
\hline F2-Acceptance & Participant's meditation experience (years) & $0.30 *$ \\
\hline F1-Awareness & Participant's weekly meditation time (minutes] & 0.03 \\
\hline F2-Acceptance & Participant's weekly meditation time (minutes) & 0.23 \\
\hline
\end{tabular}

Note: $* p<.05 ; * * p<.01 ; * * *<.001 ; * * * * p<.0001$. GSI, global severity index; CHIME, Comprehensive Inventory of Mindfulness Experiences; $E S M$, experience sampling method; $S E K$, Selbsteinschätzung emotionaler Kompetenzen; $S C L$, Symptom Checklist; $M$, mean; $S D$, standard deviation

Comprehensive Inventory of Mindfulness Experiences (CHIME). The six items of the adapted instrument CHIMEESM could be parsimoniously summarized by two factors, F1-Awareness and F2-Acceptance. F1-Awareness designates a state of recognizing, with awareness, inner bodily processes, environmental stimuli, and own thoughts and feelings. F2Acceptance means non-judgmental acceptance, when an individual also maintains openness in the face of intruding thoughts, memories, or emotions. These factors were meaningfully associated to the scales of the trait mindfulness inventory CHIME as well as to standard questionnaires assessing personality traits, psychopathological symptoms, and emotion regulation skills. We consequently assumed that this instrument could be implemented in an ESM context, promising reliable and valid assessments of mindfulness in the field. The correlative descriptions were also consistent with findings that mindfulness was associated with less psychological distress, depression, and anxiety (Bergomi et al., 2014), with age and personality traits (Giluk, 2009), and with better emotion regulation skills (Guendelman et al., 2017). 
Table 4 Hierarchical models of dependent variables positive affect (model 1, hypothesis H1a), negative affect (model 2, hypothesis H1b), and perceived stress (hypothesis H2)

\begin{tabular}{|c|c|c|c|c|c|c|c|c|c|}
\hline \multirow[b]{2}{*}{ Fixed effect } & \multicolumn{3}{|c|}{$\begin{array}{l}\text { Model } 1(n=2024) \\
\text { Positive affect }\end{array}$} & \multicolumn{3}{|c|}{$\begin{array}{l}\text { Model } 2 \text { ( } n=2024) \\
\text { Negative affect }\end{array}$} & \multicolumn{3}{|c|}{$\begin{array}{l}\text { Model } 3(n=2033) \\
\text { Perceived stress }\end{array}$} \\
\hline & $\beta$ & & $t$ & $\beta$ & & $t$ & $\beta$ & & $z$ \\
\hline Intercept & 3.29 & & $71.31 * * * *$ & 1.36 & & $45.85 * * * *$ & -0.19 & & -1.60 \\
\hline F1-Awareness & 0.10 & & $4.77 * * * *$ & - & & - & -0.14 & & $-2.51^{*}$ \\
\hline F2-Acceptance & 0.07 & & $5.66^{* * * * *}$ & -0.13 & & $-11.04 * * * *$ & -0.22 & & $-6.57 * * * *$ \\
\hline Random effect & Var & SE & Var \% & Var & SE & Var $\%$ & Var & $\mathrm{SD}$ & \\
\hline \multicolumn{10}{|l|}{ Level 2} \\
\hline Participant [intercept] & 0.10 & 0.02 & 21.2 & 0.04 & 0.009 & 23.9 & 0.66 & 0.81 & \\
\hline Participant X F1-Awareness [slope] & 0.01 & 0.00 & 2.7 & - & - & - & 0.05 & 0.23 & \\
\hline Participant X F2-Acceptance [slope] & 0.002 & 0.00 & 0.5 & 0.01 & 0.001 & 2.9 & - & - & - \\
\hline \multicolumn{10}{|l|}{ Level 1} \\
\hline Residual & 0.37 & 0.01 & 75.7 & 0.18 & 0.006 & 73.3 & & & \\
\hline
\end{tabular}

Var, variance component; SE, standard error; SD, standard deviation; Var \%, percentage of total variance; $n$, number of observations $* p<.05 ; * * * p<.0001$

The negative correlation between F1-Awareness and education level was unexpected, as higher education among meditators is often found in Western societies. The correlation resulted especially from the group with the "lowest" education, who had the highest awareness ratings. Interestingly, this group also had the highest mean age. The correlation may be due to a selection bias.

The ESM part of the study generated associations of mindfulness with the momentary affectivity and stress perceived by participants as anticipated by hypotheses. The two mindfulness factors were highly significantly linked with Positive affect, and we found large negative associations of F2Acceptance with Negative affect and with Perceived stress (Fig. 2). Especially the latter two associations may mean that meditators could regulate negative emotions by Acceptance and to some degree also by Awareness. This corroborates

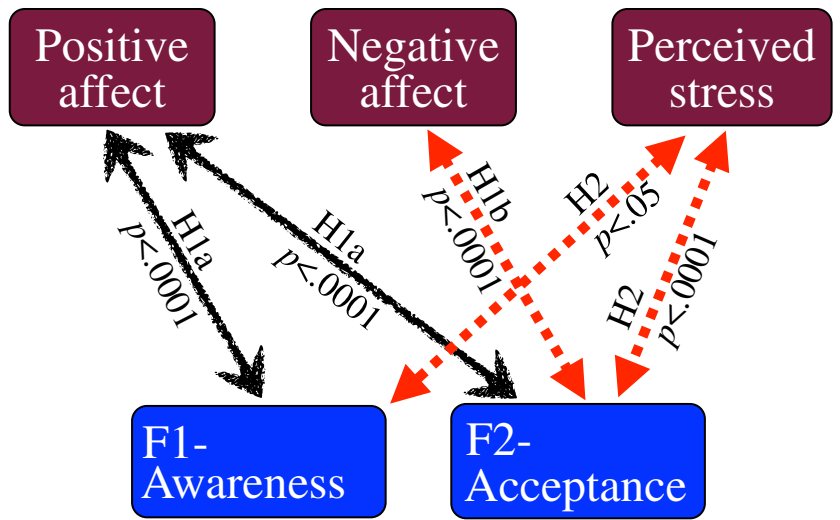

Fig. 2 Results of testing of hypotheses $\mathrm{H} 1 \mathrm{a}, \mathrm{H} 1 \mathrm{~b}$, and $\mathrm{H} 2$ in schematic presentation. (Red/broken) Arrows indicate (negatively) significant fixed effects in hierarchical linear models. The respectively supported hypothesis and significance level are printed next to arrows. $\mathrm{H} 1 \mathrm{a}, \mathrm{H} 1 \mathrm{~b}$, and $\mathrm{H} 2$ refer to Table 4 findings that mindfulness facets may be connected with resilience, which is defined as a person's capability to withstand, and cope with, adversity and critical situations and remain psychologically intact in the face of problematic circumstances and stress. Chin et al. (2019) found that mindfulness-based stress reduction interventions (MBSR) focusing on monitoring and acceptance (Monitor and Acceptance Theory (MAT): Lindsay \& Creswell, 2019) fostered stress resilience, leading to lower stress ratings and fewer reported stressful events in daily life. Our finding is also consistent with Wright and Schutte (2014), who observed that higher mindfulness was associated with better pain resilience and lowered experience of pain.

In addition to the multilevel models considering ESM assessments made at the same time-point, which are summarized in Figure 2, we conducted lagged models to refine the results by Granger causality. Granger causality means that a significant time-lagged association, i.e., when some variable A is assessed at time $t-1$ prior to variable B assessed at time $t$, may point to A's causal impact on B, unless third-variable effects on both A and B are present. This approach showed that the causal links between mindfulness and affect were likely of a bidirectional nature: mindfulness influencing affect and vice versa. Stress ratings, however, were not Granger causally connected to any of the state mindfulness facets. Specifically, F2-Acceptance reduced subsequent Negative affect, but positive and negative affect also had impacts on subsequent mindfulness. Negative affect attenuated F2Acceptance, and Positive affect attenuated F1-Awareness. We interpret these findings as preliminary evidence that mindfulness may actively reduce Negative affect consistent with hypothesis $3 b$. We however also found support for affect limiting mindfulness. Astonishingly, both affective valences, 
Table 5 Time-lagged models: hierarchical models of dependent variables Positive affect (model 4, hypothesis H3a), Negative affect (model 5, hypothesis H3b), and Perceived stress (model 6, hypothesis H4)

\begin{tabular}{|c|c|c|c|c|c|c|c|c|c|}
\hline \multirow[b]{2}{*}{ Fixed effect } & \multicolumn{3}{|c|}{$\begin{array}{l}\text { Model } 4 \text { ( } n=1539) \\
\text { Positive affect }\end{array}$} & \multicolumn{3}{|c|}{$\begin{array}{l}\text { Model } 5 \text { ( } n=1539) \\
\text { Negative affect }\end{array}$} & \multicolumn{3}{|c|}{$\begin{array}{l}\text { Model } 6(n=1543) \\
\text { Perceived stress }\end{array}$} \\
\hline & $\beta$ & & $t$ & $\beta$ & & $t$ & $\beta$ & & $z$ \\
\hline Intercept & 3.28 & & $67.02 * * * *$ & 1.34 & & $46.49 * * * *$ & -0.82 & & $-5.22 * * * *$ \\
\hline F1-Awareness $(t-1)$ & -0.01 & & -0.92 & - & & - & -0.04 & & -0.77 \\
\hline F2-Acceptance $(t-1)$ & - & & - & -0.02 & & $-2.08^{*}$ & - & & - \\
\hline Positive affect $(t-1)$ & 0.15 & & $5.85 * * * *$ & - & & - & - & & - \\
\hline Negative affect $(t-1)$ & - & & - & 0.20 & & $5.77 * * * *$ & - & & - \\
\hline Perceived stress $(t-1)$ & - & & - & - & & - & 0.33 & & $5.32 * * * *$ \\
\hline Random effect & Var & SE & $\operatorname{Var} \%$ & Var & SE & $\operatorname{Var} \%$ & Var & SD & \\
\hline \multicolumn{10}{|l|}{ Level 2} \\
\hline Participant [intercept] & 0.11 & 0.03 & 21.4 & 0.04 & 0.009 & 16.8 & 0.48 & 0.69 & \\
\hline Participant X F1-Awareness $(t-1)$ [slope] & - & - & - & - & - & - & - & - & \\
\hline Participant X F2-Acceptance $(t-1)$ [slope] & - & - & - & - & - & - & - & - & \\
\hline \multicolumn{10}{|l|}{ Level 1} \\
\hline Residual & 0.41 & 0.01 & 78.6 & 0.18 & 0.007 & 83.2 & & & \\
\hline
\end{tabular}

Var, variance component; SE, standard error; SD, standard deviation; Var $\%$, percentage of total variance; $n$, number of observations. ** $p<.01$, **** $p<$ .0001

Predictor variables are lagged; $(t-1)$ means the variable of the previous prompt. Only the respective AIC-optimal model of each dependent variable is shown

positive and negative, showed this attenuating effect on mindfulness. Thus the results from same-time models, which largely supported hypotheses, should be viewed in the light of Granger causality, which supported only one causal impact of mindfulness, but in addition indicated that causal sequences may also have acted in reverse (Fig. 3). Such bidirectional effects between affect and mindfulness are in contrast to how several studies have interpreted the association between mindfulness and affect, namely as an unidirectional effect of mindfulness on affect (e.g., Giluk, 2009; Keng et al., 2011).

Table 6 Time-lagged models: hierarchical models of dependent variables mindfulness factors F1-Awareness and F2-Acceptance

\begin{tabular}{|c|c|c|c|c|c|c|c|c|c|c|c|c|}
\hline \multirow[b]{2}{*}{ Fixed effect } & \multicolumn{3}{|c|}{$\begin{array}{l}\text { Model } 7(n=1540) \\
\text { F1-Awareness }\end{array}$} & \multicolumn{3}{|c|}{$\begin{array}{l}\text { Model } 8(n=1540) \\
\text { F2-Acceptance }\end{array}$} & \multicolumn{3}{|c|}{$\begin{array}{l}\text { Model } 9(n=1535) \\
\text { F1-Awareness }\end{array}$} & \multicolumn{3}{|c|}{$\begin{array}{l}\text { Model } 10(n=1540) \\
\text { F2-Acceptance }\end{array}$} \\
\hline & \multicolumn{2}{|l|}{$\beta$} & $\mathrm{t}$ & \multicolumn{2}{|l|}{$\beta$} & $\mathrm{t}$ & \multicolumn{2}{|l|}{$\beta$} & $\mathrm{t} / \mathrm{F}$ & \multicolumn{2}{|l|}{$\beta$} & $\mathrm{t} / \mathrm{F}$ \\
\hline Intercept & -0.04 & & 0.78 & 0.11 & & 0.90 & -0.02 & & $t=-0.13$ & 0.14 & & $t=1.28$ \\
\hline Positive affect $(t-1)$ & -0.14 & & $-2.95 * *$ & - & & - & - & & - & - & & - \\
\hline Negative affect $(t-1)$ & - & & - & -0.33 & & $-3.16^{* *}$ & - & & - & - & & - \\
\hline Perceived stress $(t-1)$ & - & & - & - & & - & & & $F=0.15$ & & & $F=1.30$ \\
\hline F1-Awareness $(t-1)$ & 0.05 & & 1.94 & - & & - & 0.09 & & $t=2.71^{* *}$ & - & & - \\
\hline F2-Acceptance $(t-1)$ & - & & - & 0.15 & & $5.02 * * * *$ & - & & - & 0.19 & & $t=9.22 * * * *$ \\
\hline Random effect & Var & SE & $\operatorname{Var} \%$ & Var & SE & $\operatorname{Var} \%$ & Var & SE & Var $\%$ & Var & SE & Var \% \\
\hline \multicolumn{13}{|l|}{ Level 2} \\
\hline Participant [intercept] & 0.93 & 0.19 & 41.7 & 0.68 & 0.15 & 23.3 & 0.82 & 0.18 & 38.6 & 0.37 & 0.10 & 14.2 \\
\hline Participant X F1-Awareness $(t-1)$ [slope] & - & - & - & - & - & - & - & - & - & - & - & - \\
\hline Participant X F2-Acceptance $(t-1)$ [slope] & - & - & - & - & - & - & - & - & - & - & - & - \\
\hline \multicolumn{13}{|l|}{ Level 1} \\
\hline Residual & 1.30 & 0.05 & 58.3 & 2.23 & 0.08 & 76.7 & 1.31 & 0.05 & 61.4 & 2.62 & 0.08 & 85.8 \\
\hline
\end{tabular}

Var, variance component; SE, standard error; Var $\%$, percentage of total variance; $n$, number of observations. $* * p<.01, * * * * p<.0001$

Predictor variables Positive affect (model 7, hypothesis H3a), Negative affect (model 8, hypothesis H3b), and Perceived stress (hypothesis H4) are lagged; $(t-1)$ means the variable of the previous prompt is used. Only the respective AIC-optimal model of each dependent variable is shown 
Fig. 3 Results of time-lagged tests (hypotheses H3a, H3b, H4) in schematic presentation. Red/ broken arrows indicate negatively significant fixed effects in hierarchical linear models addressing Granger causal relationships. The respectively supported hypothesis and significance level are printed next to arrows. $\mathrm{H} 3 \mathrm{a}, \mathrm{H} 3 \mathrm{~b}$, and $\mathrm{H} 4$ refer to Tables 5 and 6 ; $\mathrm{H} 4$ was not supported prompt $t$

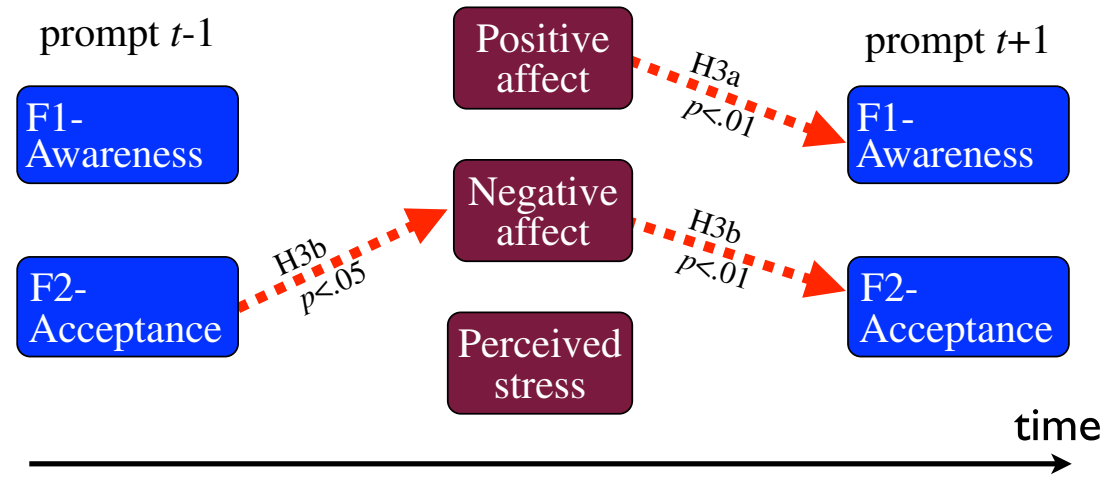

Our bidirectional findings however accorded with the diary study of Brockman et al. (2017). The present findings suggest that in meditators positive as well as negative affective states may turn out to compromise mindful states.

To date, still only a few studies have examined mindfulness using an ESM approach with relatively high sampling rate. By investigating mindfulness as a state, we were able to look into the associations between mindfulness, affect, and stress within, rather than merely between, participants. It may be emphasized that the two mindfulness facets as well as the two affect scores, respectively, were not intercorrelated, so that the regression models were not trivially dependent, and multicollinearity was ruled out. The inclusion of meditators has presumably increased the validity of assessments because of meditators' higher engagement and their preexisting acquaintance with the mindfulness construct. Since participants were surveyed under daily-life circumstances without external interventions, this inquiry exhibited high external validity and diminished the possible influence of systematic third variables that would compromise the interpretation of time-lagged results. All in all, to our knowledge, this is the first study with meditators that has investigated the time-lagged associations of mindfulness with affect and stress at a state level.

In conclusion, this study provided a nuanced account of mindfulness in processes of daily life. Results have implications for applied fields such as psychotherapy, where mindfulness and resilience were found to be attributes of particularly efficient therapists (the topic of so-called therapist effects: Lutz \& Barkham, 2015; Pereira et al., 2017). Our finding that negative affect is damped by Acceptance and that negative affect reciprocally damps Acceptance may offer an explanation why mindfulness and resilience are aligned in successful psychotherapists and also protect against professional burnout. A system-theoretical "minimal model" of therapeutic intervention (Tschacher \& Haken, 2019) has claimed on ground of theoretical considerations that therapists should exhibit "slow" dynamics in order to be effective. Given the potentially stressful emotional experiences surfacing in the psychotherapy session, a therapist must possess or acquire the ability to deal with stress and remain competent when encountering adverse situations linked with negative valence (i.e., therapists must be resilient). Instead of responding to such stimuli too quickly, a therapist should be accepting and thereby reduce his/her own negative affect. Such therapists are "slow" in the sense of Tschacher and Haken's model. This is supported by mindfulness as one's ability to not automatically respond to adversity, but maintain a state of nonjudgmental orientation to the present moment. Consequently therapists, and not only clients, can profit from mindfulness and especially from acceptance trainings.

\section{Limitations and Future Research Directions}

Our analyses underlie some limitations. First, mindfulness as a state was assessed with a questionnaire not previously and independently validated, and factorization considered only the between-person variance thus neglecting possible nonergodicity and intraindividual variation (Molenaar, 2004). Second, the modeling of lagged effects in Tables 5 and 6 was conducted with reduced statistical power ( $n \approx 1500$ instead of $n \approx 2000$ of same-time models), because those lagged variables referring to assessments made on another day were not considered, since such lag intervals would have lasted a whole night. Even the 2-h intervals between the ESM surveys in the daytime may have been rather long for effects to be detected: the moment-centered experienced qualities of affect, stress, and mindfulness may have largely subsided during such intervals. Short-term causal effects were indeed suggested by experimental laboratory studies. Thus we may have missed some time-lagged effects. Third, lagged analyses in general must be regarded merely as surrogates of causality since the influence of a third variable or process cannot be ruled out (Eichler, 2012). Finally, our sample was limited by the relatively small number of participants. Owing to the inclusion criterion of meditation experience, our sample is selective, so that generalization to the general population must remain tentative. 
Future research may study the proposed time-lagged effects of mindfulness and affect in the context of psychotherapy and counseling research. In many ambulatory psychotherapy settings, session and pre-session reports are already implemented as standard quality assessments, which would lend themselves to the exploration of mindfulness effects in complete psychotherapy courses. It would be of high theoretical and practical interest to better explore the temporal dynamics of mindfulness and affectivity of both clients and therapists/ coaches to better understand helpful interactions and advance our knowledge about successful therapists.

Author Contribution NL recruited participants and supervised data acquisition. NL and WT collaborated with the design and writing of the study. WT performed the analyses and wrote the final manuscript. All authors approved the final version of the manuscript for submission.

Funding Open Access funding provided by Universität Bern.

\section{Declarations}

Ethics Approval and Consent to Participate The authors confirm that the study was conducted in full concordance with Swiss research ethics legislation (Humanforschungsgesetz) and the 1964 Helsinki Declaration. Participants' informed consent was obtained before initiation of the study.

Conflict of Interest The authors declare no competing interests.

Open Access This article is licensed under a Creative Commons Attribution 4.0 International License, which permits use, sharing, adaptation, distribution and reproduction in any medium or format, as long as you give appropriate credit to the original author(s) and the source, provide a link to the Creative Commons licence, and indicate if changes were made. The images or other third party material in this article are included in the article's Creative Commons licence, unless indicated otherwise in a credit line to the material. If material is not included in the article's Creative Commons licence and your intended use is not permitted by statutory regulation or exceeds the permitted use, you will need to obtain permission directly from the copyright holder. To view a copy of this licence, visit http://creativecommons.org/licenses/by/4.0/.

\section{References}

Analayo, B. (2019). Adding historical depth to definitions of mindfulness. Current Opinion in Psychology, 28, 11-14.

Anderson, N. D., Lau, M. A., Segal, Z. V., \& Bishop, S. R. (2007). Mindfulness-based stress reduction and attentional control. Clinical Psychology and Psychotherapy, 14(6), 449-463. https:// doi.org/10.1002/cpp.544.

Arch, J. J., \& Craske, M. G. (2006). Mechanisms of mindfulness: Emotion regulation following a focused breathing induction. Behaviour Research and Therapy, 44(12), 1849-1858. https://doi. org/10.1016/j.brat.2005.12.007.

Baer, R. (2019). Assessment of mindfulness by self-report. Current Opinion in Psychology, 28, 42-48.

Baer, R. A., Smith, G. T., Hopkins, J., Krietemeyer, J., \& Toney, L. (2006). Using self-report assessment methods to explore facets of mindfulness. Assessment, 13(1), 27-45. https://doi.org/10.1177/ 1073191105283504

Baer, R. A., Smith, G. T., Lykins, E., Button, D., Krietemeyer, J., Sauer, S., Walsh, E., Duggan, D., \& Williams, J. M. (2008). Construct validity of the five facet mindfulness questionnaire in meditating and nonmeditating samples. Assessment, 15(3), 329-342. https:// doi.org/10.1177/1073191107313003.

Bates, D., Maechler, M., Bolker, B. M., \& Walker, S. C. (2015). Fitting linear mixed-effects models using lme4. Journal of Statistical Software, 67(1). https://doi.org/10.18637/jss.v067.i01.

Belzer, F., Schmidt, S., Lucius-Hoene, G., Schneider, J. F., OrellanaRios, C. L., \& Sauer, S. (2013). Challenging the construct validity of mindfulness assessment - A cognitive interview study of the Freiburg Mindfulness Inventory. Mindfulness, 4, 33-44.

Bergomi, C., Tschacher, W., \& Kupper, Z. (2013). The assessment of mindfulness with self-report measures: Existing scales and open issues. Mindfulness, 4(3), 191-202. https://doi.org/10.1007/ s12671-012-0110-9.

Bergomi, C., Tschacher, W., \& Kupper, Z. (2014). Konstruktion und erste Validierung eines Fragebogens zur umfassenden Erfassung von Achtsamkeit. Diagnostica, 60(3), 111-125. https://doi.org/10. 1026/0012-1924/a000109.

Bergomi, C., Tschacher, W., \& Kupper, Z. (2015). Meditation practice and self-reported mindfulness: A cross-sectional investigation of meditators and non-meditators using the Comprehensive Inventory of Mindfulness Experiences (CHIME). Mindfulness, 6(6), 14111421. https://doi.org/10.1007/s12671-015-0415-6.

Berking, M., \& Znoj, H. (2008). Entwicklung und Validierung eines Fragebogens zur standardisierten Selbsteinschätzung emotionaler Kompetenzen (SEK-27). Zeitschrift für Psychiatrie, Psychologie und Psychotherapie, 56, 141-153.

Bishop, S. R., Lau, M., Shapiro, S., Carlson, L., Anderson, N. D., Carmody, J., Segal, Z. V., Abbey, S., Speca, M., Velting, D., \& Devins, G. (2004). Mindfulness: A proposed operational definition. Clinical Psychology: Science and Practice, 11(3), 230-241. https:// doi.org/10.1093/clipsy/bph077.

Blanke, E. S., Riediger, M., \& Brose, A. (2018). Pathways to happiness are multidirectional: Associations between state mindfulness and everyday affective experience. Emotion, 18(2), 202-211. https:// doi.org/10.1037/emo0000323.

Bodhi, B. (2011). What does mindfulness really mean? A canonical perspective. Contemporary Buddhism, 12(1), 19-39. https://doi.org/10. 1080/14639947.2011.564813

Bonito, J. A., Ruppel, E. K., \& Keyton, J. (2012). Reliability estimates for multilevel designs in group research. Small Group Research, 43, 443-467. https://doi.org/10.1177/1046496412437614.

Borkenau, P., \& Ostendorf, F. (1993). NEO-Fünf-Faktoren Inventar (NEO-FFI). Hogrefe.

Brockman, R., Ciarrochi, J., Parker, P., \& Kashdan, T. (2017). Emotion regulation strategies in daily life: mindfulness, cognitive reappraisal and emotion suppression. Cognitive Behaviour Therapy, 46(2), 91113. https://doi.org/10.1080/16506073.2016.1218926.

Broderick, P. C. (2005). Mindfulness and coping with dysphoric mood: Contrasts with rumination and distraction. Cognitive Therapy and Research, 29(5), 501-510. https://doi.org/10. 1007/s10608-005-3888-0.

Brown, K. W., \& Ryan, R. M. (2003). The benefits of being present: Mindfulness and its role in psychological well-being. Journal of Personality and Social Psychology, 84(4), 822-848. https://doi. org/10.1037/0022-3514.84.4.822.

Brown, D. B., Bravo, A. J., Roos, C. R., \& Pearson, M. R. (2015a). Five facets of mindfulness and psychological health: Evaluating a psychological model of the mechanisms of mindfulness. Mindfulness, 6(5), 1021-1032. https://doi.org/10.1007/s12671-014-0349-4.

Brown, K. W., Creswell, J. D., \& Ryan, R. M. (2015b). Introduction: the evolution of mindfulness science. In K. W. Brown, J. D. Creswell, \& 
R. M. Ryan (Eds.), Handbook of mindfulness. Theory, research, and practice (pp. 1-6). Guilford Press.

Cardaciotto, L., Herbert, J. D., Forman, E. M., Moitra, E., \& Farrow, V. (2008). The assessment of present-moment awareness and acceptance. The Philadelphia Mindfulness Scale. Assessment, 15(2), 204 223. https://doi.org/10.1177/1073191107311467.

Chadwick, P., Hember, M., Symes, J., Peters, E., Kuipers, E., \& Dagnan, D. (2008). Responding mindfully to unpleasant thoughts and images: Reliability and validity of the Southampton Mindfulness Questionnaire (SMQ). British Journal of Clinical Psychology, 47(4), 451-455. https://doi.org/10.1348/014466508X314891.

Chin, B., Lindsay, E. K., Greco, C. M., Brown, K. W., Smyth, J. M., Wright, A. G. C., \& Creswell, J. D. (2019). Psychological mechanisms driving stress resilience in mindfulness training: A randomized controlled trial. Health Psychology, 38(8), 759-768. https://doi. org/10.1037/hea0000763.

Delespaul, P. A. E. G. (1995). Assessing schizophrenia in daily life: The experience sampling method. Maastricht: University of Limburg.

Derogatis, L. R. (1977). SCL-90-R, administration, scoring \& procedures manual-I for the R(evised) version. John Hopkins University School of Medicine.

Ditto, B., Eclache, M., \& Goldman, N. (2006). Short-term autonomic and cardiovascular effects of mindfulness body scan meditation. Annals of Behavioral Medicine, 32(3), 227-234. https://doi.org/10.1207/ s15324796abm3203_9.

Eichler, M. (2012). Causal inference in time series analysis. In C. Berzuini, P. Dawid, \& L. Bernardinelli (Eds.), Causality: statistical perspectives and applications (pp. 327-354). John Wiley.

Erisman, S. M., \& Roemer, L. (2010). A preliminary investigation of the effects of experimentally induced mindfulness on emotional responding to film clips. Emotion, 10(1), 72-82. https://doi.org/10. 1037/a0017162.

Garland, E. L., Geschwind, N., Peeters, F., \& Wichers, M. (2015). Mindfulness training promotes upward spirals of positive affect and cognition: Multilevel and autoregressive latent trajectory modeling analyses. Frontiers in Psychology, 5, 15. https://doi.org/10. 3389/fpsyg.2015.00015.

Geschwind, N., Peeters, F., Drukker, M., van Os, J., \& Wichers, M. (2011). Mindfulness training increases momentary positive emotions and reward experience in adults vulnerable to depression: A randomized controlled trial. Journal of Consulting and Clinical Psychology, 79(5), 618-628. https://doi.org/10.1037/a0024595.

Gethin, R. M. L. (2001). The Buddhist path to awakening. Oneworld.

Giluk, T. L. (2009). Mindfulness, Big Five personality, and affect: A meta-analysis. Personality and Individual Differences, 47(8), 805811. https://doi.org/10.1016/j.paid.2009.06.026.

Gotink, R. A., Hermans, K. S., Geschwind, N., De Nooij, R., De Groot, W. T., \& Speckens, A. E. (2016). Mindfulness and mood stimulate each other in an upward spiral: a mindful walking intervention using experience sampling. Mindfulness, 7(5), 1114-1122. https://doi.org/ 10.1007/s12671-016-0550-8.

Grossman, P. (2008). On measuring mindfulness in psychosomatic and psychological research. Journal of Psychosomatic Research, 64(4), 405-408. https://doi.org/10.1016/j.jpsychores.2008.02.001.

Guendelman, S., Medeiros, S., \& Rampes, H. (2017). Mindfulness and emotion regulation: Insights from neurobiological, psychological, and clinical studies. Frontiers in Psychology, 8, 220. https://doi. org/10.3389/fpsyg.2017.00220.

Harvey, P. (2013). An introduction to Buddhism: Teachings, history and practices (2nd ed.). Cambridge University Press.

Hill, C. L. M., \& Updegraff, J. A. (2011). Mindfulness and its relationship to emotional regulation. Emotion, 12(1), 81-90. https://doi.org/10. 1037/a0026355.

Johnson, C., Burke, C., Brinkman, S., \& Wade, T. (2017). Development and validation of a multifactor mindfulness scale in youth: The Comprehensive Inventory of Mindfulness Experiences-
Adolescents (CHIME-A). Psychological Assessment, 29, 264-281. https://doi.org/10.1037/pas0000342.

Keng, S.-L., Smoski, M. J., \& Robins, C. J. (2011). Effects of mindfulness on psychological health: A review of empirical studies. Clinical Psychology Review, 31(6), 1041-1056. https://doi.org/10.1016/j. cpr.2011.04.006.

Kockler, T. D., Tschacher, W., Santangelo, P. S., Limberger, M. F., \& Ebner-Priemer, U. W. (2017). Specificity of emotion sequences in borderline personality disorder compared to posttraumatic stress disorder, bulimia nervosa, and healthy controls: An e-diary study. Borderline Personality Disorder and Emotion Dysregulation, 4, 26. https://doi.org/10.1186/s40479-017-0077-1.

Krohne, H. W., Egloff, B., Kohlmann, C.-W., \& Tausch, A. (1996). Untersuchungen mit einer deutschen Version der "Positive and Negative Affect Schedule" (PANAS). Diagnostica, 42(2), 139-156.

Kuranova, A., Booij, S. H., Menne-Lothmann, C., Decoster, J., van Winkel, R., Delespaul, P., De Hert, M., Derom, C., Thiery, E., Rutten, B. P. F., Jacobs, N., van Os, J., Wigman J. T. W., \& Wichers, M. (2020). Measuring resilience prospectively as the speed of affect recovery in daily life: a complex systems perspective on mental health. BMC Medicine, 18(36). https://doi.org/10.1186/ s12916-020-1500-9

Lindsay, E. K., \& Creswell, J. D. (2019). Mindfulness, acceptance, and emotion regulation: Perspectives from Monitor and Acceptance Theory (MAT). Current Opinion in Psychology, 28, 120-125.

Lutz, W., \& Barkham, M. (2015). Therapist effects. In R. L. Cautin \& S. O. Lilienfeld (Eds.), The encyclopedia of clinical psychology (pp. 16). Hoboken: Wiley.

Molenaar, P. C. M. (2004). A manifesto on psychology as idiographic science: Bringing the person back into scientific psychology, this time forever. Measurement Interdisciplinary Research and Perspectives, 2(4), 201-218. https://doi.org/10.1207/ s15366359mea0204_1.

Nyklícek, I., \& Kuijpers, K. F. (2008). Effects of mindfulness-based stress reduction intervention on psychological well-being and quality of life: Is increased mindfulness indeed the mechanism? Annals of Behavioral Medicine, 35(3), 331-340. https://doi.org/10.1007/ s12160-008-9030-2.

Pereira, J.-A., Barkham, M., Kellett, S., \& Saxon, D. (2017). The role of practitioner resilience and mindfulness in effective practice: A practice-based feasibility study. Administration and Policy in Mental Health and Mental Health Services Research, 44(5), 691704. https://doi.org/10.1007/s10488-016-0747-0.

Petrowski, K., Schmalbach, B., Kliem, S., Hinz, A., \& Brähler, E. (2019). Symptom-Checklist-K-9: Norm values and factorial structure in a representative German sample. PloS One, 14(4), e0213490. https:// doi.org/10.1371/journal.pone.0213490.

Rammstedt, B., \& John, O. P. (2005). Kurzversion des Big Five Inventory (BFI-K). Diagnostica, 51, 195-206. https://doi.org/10. 1026/0012-1924.51.4.195.

Sauer, S., Walach, H., Schmidt, S., Hinterberger, T., Lynch, S., Büssing, A., \& Kohls, N. (2013). Assessment of mindfulness: Review on state of the art. Mindfulness, 4(1), 3-17. https://doi.org/10.1007/ s12671-012-0122-5.

Sedlmeier, P., Eberth, J., Schwarz, M., Zimmermann, D., Haarig, F., Jaeger, S., \& Kunze, S. (2012). The psychological effects of meditation: A meta-analysis. Psychological Bulletin, 138(6), 1139-1171. https://doi.org/10.1037/a0028168.

Shapiro, S. L., Brown, K. W., \& Biegel, G. M. (2007). Teaching self-care to caregivers: Effects of mindfulness-based stress reduction on the mental health of therapists in training. Training and Education in Professional Psychology, 1(2), 105-115. https://doi.org/10.1037/ 1931-3918.1.2.105.

Shiffman, S., Stone, A. A., \& Hufford, M. R. (2008). Ecological momentary assessment. Annual Review of Clinical Psychology, 4, 1-32. https://doi.org/10.1146/annurev.clinpsy.3.022806.091415. 
Shoham, A., Goldstein, P., Oren, R., Spivak, D., \& Bernstein, A. (2017). Decentering in the process of cultivating mindfulness: An experience-sampling study in time and context. Journal of Consulting and Clinical Psychology, 85(2), 123-134. https://doi. org/10.1037/ccp0000154.

Snippe, E., Dziak, J. J., Lanza, S. T., Nyklícek, I., \& Wichers, M. (2017). The shape of change in perceived stress, negative affect, and stress sensitivity during mindfulness-based stress reduction. Mindfulness, $8,728-736$.

Thompson, E. R. (2007). Development and validation of an internationally reliable short-form of the positive and negative affect schedule (PANAS). Journal of Cross-Cultural Psychology, 38(2), 227-242. https://doi.org/10.1177/0022022106297301.

Tröndle, M., Greenwood, S., Kirchberg, V., \& Tschacher, W. (2014). An integrative and comprehensive methodology for studying aesthetic experience in the field: Merging movement tracking, physiology, and psychological data. Environment and Behavior, 46(1), 102135. https://doi.org/10.1177/0013916512453839.

Trull, T., \& Ebner-Priemer, U. W. (2014). The role of ambulatory assessment in psychological science. Current Directions in Psychological Science, 23(6), 466-470. https://doi.org/10.1177/ 0963721414550706.

Tschacher, W., \& Haken, H. (2019). The process of psychotherapy: Causation and chance. Springer Nature. https://doi.org/10.1007/ 978-3-030-12748-0.
Van der Gucht, K., Dejonckheere, E., Erbas, Y., Takano, K., Vandemoortele, M., Maex, E., Raes, F., \& Kuppens, P. (2019). An experience sampling study examining the potential impact of a mindfulness-based intervention on emotion differentiation. Emotion, 19(1), 123-131. https://doi.org/10.1037/emo0000406.

Walsh, K. M., Saab, B. J., \& Farb, N. A. (2019). Effects of a mindfulness meditation app on subjective well-being: Active randomized controlled trial and experience sampling study. JMIR Mental Health, 6(1), e10844. https://doi.org/10.2196/10844.

Weinstein, N., Brown, K. W., \& Ryan, R. M. (2009). A multi-method examination of the effects of mindfulness on stress attribution, coping, and emotional well-being. Journal of Research in Personality, 43(3), 374-385. https://doi.org/10.1016/j.jrp.2008.12.008.

Wenzel, M., Rowland, Z., \& Kubiak, T. (2020). How mindfulness shapes the situational use of emotion regulation strategies in daily life. Cognition and Emotion. https://doi.org/10.1080/ 02699931.2020 .1758632$.

Wright, C. J., \& Schutte, N. S. (2014). The relationship between greater mindfulness and less subjective experience of chronic pain: Mediating functions of pain management self-efficacy and emotional intelligence. Australian Journal of Psychology, 66(3), 181-186. https://doi.org/10.1111/ajpy.12041.

Publisher's Note Springer Nature remains neutral with regard to jurisdictional claims in published maps and institutional affiliations. 